\title{
Using eddy geopotential height to measure the western North Pacific subtropical high in a warming climate
}

\author{
Chao $\mathrm{He}^{1,2}$ (I) Ailan $\mathrm{Lin}^{1} \cdot$ Dejun $\mathrm{Gu}^{1} \cdot$ Chunhui $\mathrm{Li}^{1} \cdot \operatorname{Bin} \mathrm{Zheng}{ }^{1} \cdot \mathrm{Bo} \mathrm{Wu}^{2,3} \cdot$ \\ Tianjun Zhou ${ }^{2,3}$
}

Received: 5 April 2016 / Accepted: 6 November 2016/Published online: 21 November 2016

(C) The Author(s) 2016. This article is published with open access at Springerlink.com

\begin{abstract}
The western North Pacific subtropical high (WNPSH) is crucial to the East Asian summer climate, and geopotential height $(H)$ is widely used to measure the WPNSH. However, a rapidly rising trend of $H$ in the future is projected by the models from the Coupled Model Intercomparison Project Phase 5 (CMIP5). Diagnoses based on the hypsometric equation suggest that more than $80 \%$ of the rise in $H$ are attributable to zonal uniform warming. Because circulation is determined by the gradient of $H$ rather than its absolute magnitude, the spatially uniform rising trend of $H$ gives rise to difficulties when measuring the WNPSH with $H$. These difficulties include an invalid western boundary of WNPSH in the future and spurious information regarding long-term trends and interannual variability of WNPSH. Using CMIP5 model simulations and reanalysis data, the applicability of a metric based on eddy geopotential height $\left(H_{e}\right)$ to the warming climate is investigated. The results show that the $H_{e}$ metric outperforms the $H$ metric under warming climate conditions. First, the mean state rainfall- $H_{e}$ relationship is more robust than the rainfall- $H$ relationship. Second, the area, intensity, and western boundary indices of WNPSH can be effectively defined by the $H_{e}=0$-m contour in future warming climate scenarios without spurious trends. Third, the interannual variability of East Asian summer rainfall is more
\end{abstract}

Tianjun Zhou

zhoutj@lasg.iap.ac.cn

1 Guangdong Provincial Key Laboratory of Regional Numerical Weather Prediction, Institute of Tropical and Marine Meteorology (ITMM), China Meteorological Administration (CMA), Guangzhou, China

2 LASG, Institute of Atmospheric Physics (IAP), Chinese Academy of Sciences (CAS), Beijing, China

3 Joint Center for Global Change Studies (JCGCS), Beijing, China closely related to the $H_{e}$-based WNPSH indices. We recommend that the $H_{e}$ metric be adopted as an operational metric on the WNPSH under the current warming climate.

\section{Introduction}

The western North Pacific subtropical high (WNPSH) is the western extension of the North Pacific subtropical high (Yun et al. 2015). In summer, the WNPSH anchors the subtropical rain belt on its northwestern flank, where the moist southerly wind encounters mid-latitude air masses. The variability of the rain belt over East Asia is modulated by the variability of the WNPSH on intraseasonal (Zhu et al. 2003; Ren et al. 2013), interannual (Zhou and Yu 2005; Wen et al. 2015; Chen et al. 2016), and interdecadal (Gong and Ho 2002; Zhou et al. 2009; Matsumura et al. 2015) timescales. Wu et al. (2005) and Kim et al. (2012) showed that the WNPSH also regulates the genesis locations and paths of tropical cyclones over the western North Pacific (WNP). Anomalously strong or weak WNPSH causes widespread floods (Zhou and Yu 2005; Sampe and Xie 2010; Jiang et al. 2015), droughts (Park and Schubert 1997; Lin et al. 2012), and heat waves (Zhang et al. 2004; Wang et al. 2016) in East Asia.

Given the profound influence of the WNPSH on East Asian climate, great efforts have been devoted to monitoring and predicting abnormalities of the WNPSH. The WNPSH is usually measured by 500 -hPa geopotential height (abbreviated as $H$ hereafter). For example, a positive $H$ anomaly over the WNP is interpreted as an anomalously strong WNPSH and vice versa (e.g., Gong and Ho 2002; Wu and Zhou 2008; Seo et al. 2013). China Meteorological Administration (CMA) defined the area, intensity, and western boundary indices of WNPSH based on $H$ in its operational strategy. These realtime WNPSH indices are monitored (http://cmdp.ncc-cma. 
net/Monitoring/en_bulletin.php), and they are used as essential information for operational prediction of East Asian climate (Chen 1999; Liu et al. 2012).

However, it was reported that the $H$ metric of the WNPSH may be misleading under the warming climate. Changes in circulation suggest that the WNPSH weakened and retreated eastward after the late 1970s (Huang et al. 2015; Huang and Li 2015; Wu and Wang 2015), although some previous studies showed intensification and westward extension of the WNPSH after the late 1970s based on the increase of $H$ over the WNP (Gong and Ho 2002). Since the late 1970s, the zonal mean $H\left(H_{m}\right)$ over the entire subtropical northern hemisphere has risen substantially due to global warming (Yang and Sun 2003; Wu and Wang 2015). This rise does not seem related to changes in circulation, since circulation is controlled by the horizontal gradient of $H$ instead of the absolute magnitude of $H$. However, it remains unknown how fast $H$ will rise in future and whether it is related to changes in circulation.

Recent studies have proposed a new metric of the WPNSH, i.e., eddy geopotential height $\left(H_{e}\right)$, which is calculated by subtracting the simultaneous $H_{m}\left(0^{\circ} \mathrm{N}-40^{\circ} \mathrm{N}, 180^{\circ} \mathrm{W}-180^{\circ} \mathrm{E}\right.$ averaged $H$ ) from the original $H$ (Zhou et al. 2009; Huang et al. 2015; Huang and Li 2015; Wu and Wang 2015). The $H_{e}$ metric effectively captures the decadal change of the WNPSH seen in the late 1970s (Huang et al. 2015; Huang and Li 2015; Wu and Wang 2015), but it is not clear whether the $H_{e}$ metric is a good operational metric that well captures the mean state and interannual variability of the WNPSH in the warming climate. Based on the model projections of future climate from the Coupled Model Intercomparison Project Phase 5 (CMIP5) (Taylor et al. 2012) and on the reanalysis data, the current study aims to address the following questions: can we still use the $H$ metric in the warming climate? Is the $H_{e}$ metric a good substitute for the $H$ metric?

The remainder of the manuscript is organized as follows: the data, models, and methods are introduced in Sect. 2. The major difficulties in monitoring the WNPSH under the warming climate are documented in Sect. 3. A comparison between the $H_{e}$ metric and $H$ metric is documented in Sect. 4. Finally, a summary is presented in Sect. 5.

\section{Data, models, and methods}

The observational datasets used in this study include (1) monthly geopotential height, temperature, surface pressure, and wind supplied by the National Centers for Environmental Prediction/National Center for Atmospheric Research (NCEP/NCAR) (Kalnay et al. 1996) and (2) monthly precipitation from the Global Precipitation Climatology Project (GPCP) (Adler et al. 2003) and CPC Merged Analysis of Precipitation (CMAP) (Xie and Arkin 1997). Since the WNPSH has the greatest impact on East Asian climate during summer, we focus on the seasonal mean of June-JulyAugust (JJA) for all the five variables.

The outputs of 31 CMIP5 models (Taylor et al. 2012) are adopted in this study. The names for these 31 models can be found in the supplementary information of He et al. (2015). The historical experiments are adopted as a baseline for the current climate, and the Representative Concentration Pathway 4.5 (RCP4.5) and RCP8.5 experiments are selected as the possible evolution pathways of future climate. The RCP4.5 (RCP8.5) is a median (high) pathway with a radiative forcing of $4.5 \mathrm{Wm}^{-2}\left(8.5 \mathrm{Wm}^{-2}\right)$ by 2100 (Vuuren et al. 2011). For brevity, we only show figures based on RCP8.5 if they show similar spatial patterns to RCP4.5. Following the recommendation by Gleckler et al. (2008), we extract the forced response by using the multi-model median (MMM), which effectively suppresses the bias and internal variability of individual models. Although some models contain more than one ensemble member, we only use the first ensemble member (named "rlilp1" in CMIP5 convention) of each model.

According to the hypsometric equation, i.e., the integrated form of the hydrostatic equation (Holton 2004) $H$ at $p=500 \mathrm{hPa}$ is calculated as

$H=\frac{\mathrm{RT}}{g} \ln \frac{P s}{p}+H s$

where $R=287.0 \mathrm{~J} \cdot(\mathrm{kg} \mathrm{K})^{-1}$ is the gas constant of dry air and $g=9.8 \mathrm{~m} \mathrm{~s}^{-2}$ is the gravitational acceleration. $T$ stands for the vertically averaged temperature between the surface and isobaric surface of $p=500 \mathrm{hPa} . P_{S}$ stands for surface pressure, and thus, $\ln (P s / p)>0 . H_{s}$ is the geopotential height of the surface, and it is determined by topography but not affected by global warming. Since the global mean $P_{s}$ will not change because of the air-mass conservation, the increase in $T$ should result in an increase in global mean $H$. Designating the current climate with subscript 1 and the future climate with subscript 2 , the difference between the future and current climate is

$$
H_{2}-H_{1}=\frac{R}{g}\left[\left(T_{2}-T_{1}\right) \ln \frac{P s_{1}}{p}+T_{1} \ln \frac{P s_{2}}{P s_{1}}+\left(T_{2}-T_{1}\right) \ln \frac{P s_{2}}{P s_{1}}\right]
$$

As seen in the three terms on the right-hand side of Eq. (2), the change in $H$ is determined by changes in temperature, surface pressure, and the cross term due to their nonlinear effect. Similar to the decomposition of $H$ into $H=H_{m}+H_{e}$, we decompose the temperature $T$ into the zonal mean $\left(T_{m}\right)$ and eddy components $\left(T_{e}\right)$, i.e., $T=T_{m}+T_{e}$. The change in 
temperature $\left(T_{2}-T_{1}\right)$ can be broken down into zonal uniform warming $\left(T_{m 2}-T_{m 1}\right)$ and temperature pattern change
$\left(T_{e 2}-T_{e 1}\right)$. Therefore, the change in $H$ can be further decomposed.

$H_{2}-H_{1}=\frac{R}{g}\left[\left(T_{m 2}-T_{m 1}\right) \ln \frac{P s_{1}}{p}+\left(T_{e 2}-T_{e 1}\right) \ln \frac{P s_{1}}{p}+T_{1} \ln \frac{P s_{2}}{P s_{1}}+\left(T_{2}-T_{1}\right) \ln \frac{P s_{2}}{P s_{1}}\right]$

According to the four terms on the right-hand side of Eq. (3), the response of $H$ to global warming is determined by the following four factors: uniform warming, temperature pattern, surface pressure, and the cross term of the nonlinear effect.

\section{Difficulties with the $H$ metric under the warming climate}

In order to examine whether $H$ will continue rising in future, Fig. 1a shows the difference in $H$ between the RCP8.5 run (2050-2099 averaged) and the historical run (1950-1999 averaged) for the MMM. The $H$ rises by about $80 \mathrm{~m}$ over the WNP. The rise of $H$ is even stronger along the northern flank of the WNPSH. Despite $H$ rising, an anomalous cyclone is seen around the WNPSH, characterized by the weakened westerly wind around $40^{\circ} \mathrm{N}$ and weakened easterly wind near the equator. The change in circulation suggests a weakened
WNPSH. Thus, a higher $H$ does not necessarily indicate a stronger WNPSH.

To examine which terms in Eq. (3) dominate the rise of $H$, Fig. 1b-e shows the contributions of the four terms in Eq. (3) to changes in $H$, overlaid with the geostrophic wind derived from the corresponding $H$ field. A uniform increase of $H$ by $70 \mathrm{~m}$ is induced by zonal uniform warming (Fig. 1b), which contributes to more than $80 \%$ of the total increase of $H$ over the WNP. Because wind is determined by the gradient of $H$ but uniform warming makes little change to $H$ gradient, the change in wind due to uniform warming is negligible over the WNP. The change in $H$ attributable to the temperature pattern is characterized by a weakened meridional $H$ gradient on the northern flank of the WNPSH, associated with strong easterly wind anomalies (Fig. 1c). Change in surface pressure contributes to a slight increase in the meridional $H$ gradient and a slightly enhanced westerly wind on the northern flank of the WNPSH (Fig. 1d), which partially offsets the effect of temperature pattern. Changes in $H$ and wind attributable to
Fig. 1 a The MMM-projected changes in $H$ (unit $\mathrm{m}$ ) and wind (unit $\mathrm{m} / \mathrm{s}$ ) at $500 \mathrm{hPa}$, calculated as the difference between RCP8.5 and historical runs. b-e The contributions of the four terms on the right-hand side of Eq. (3) to the change of $H$, i.e., uniform warming (b), temperature pattern change (c), surface pressure change (d), and the cross term (e). f The sum of the four terms in $\mathbf{b}$ e. The blue dotted region in $\mathbf{b}-\mathbf{f}$ suggests that the contribution of the term exceeds $80 \%$ of the total increase in $H$. The vectors in $\mathbf{b}-\mathbf{f}$ are the geostrophic wind determined by the $H$ pattern; any calculated wind with a speed smaller than $0.1 \mathrm{~m} / \mathrm{s}$ is omitted. The shape of the WPNSH is indicated by the $H=5845-\mathrm{m}$ contour in historical run (white line) (a) $\mathrm{DH}$

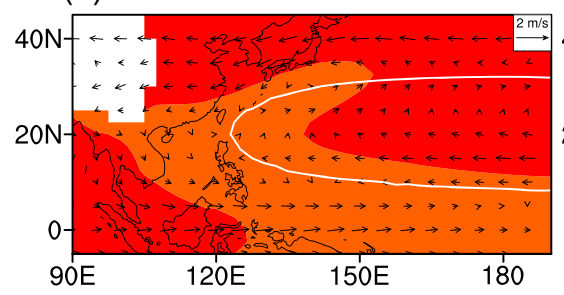

(c) $\mathrm{Te}$

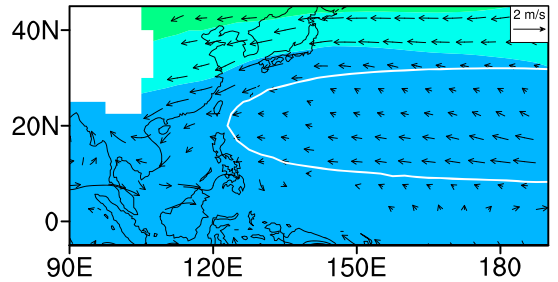

(e) $\mathrm{Cr}$

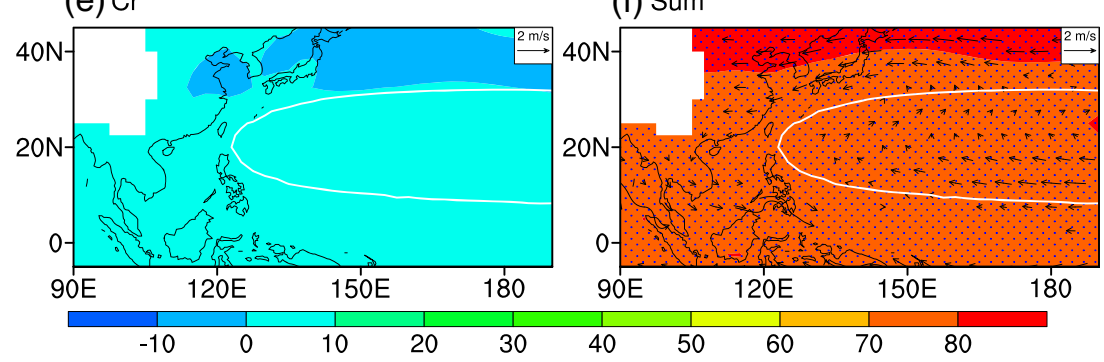

(b) $\mathrm{Tm}$

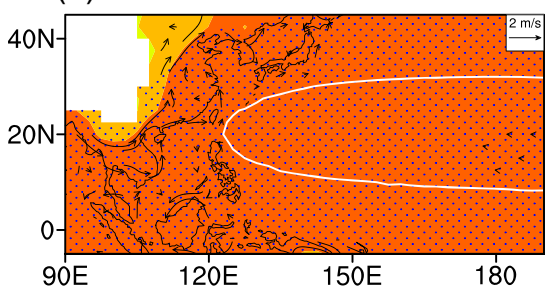

(d) Ps

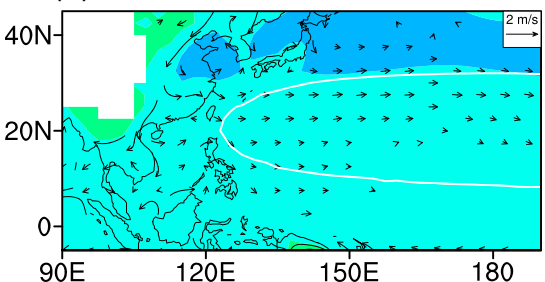

(f) Sum 
the cross term are negligible (Fig. 1e). The sum of the four aforementioned terms effectively reconstructs the total changes in $H$ and off-equatorial winds (Fig. 1f). Overall, the rise in $H$ is mostly caused by spatial uniform warming, which has negligible effects on circulation.

For the entire 2006-2099 period, the MMM-projected linear trend of $H_{m}$ is $0.44 \mathrm{~m} /$ year under RCP4.5 and $1.11 \mathrm{~m} /$ year under RCP8.5 (Fig. 2a). This trend ranges from 0.28 to $0.64 \mathrm{~m} /$ year under RCP4.5 and from 0.76 to $1.40 \mathrm{~m} /$ year under RCP8.5 among the individual models. Figure $2 \mathrm{~b}$ shows that the rise of $H_{m}$ closely follows the rise of temperature, which is consistent with the theoretical prediction according to Eq. (1). The $H_{m}$ under RCP8.5 approximates a linear increase throughout the twenty-first century, following the increase in temperature (solid and dashed red lines in Fig. 2b). Under RCP4.5, the $H_{m}$ increases rapidly during the first half of twenty-first century but slightly slows down during the second half of the twentyfirst century, also closely following the evolution of temperature (solid and dashed orange lines in Fig. 2b).

Under the warming climate, a rising $H_{m}$ causes difficulties for measuring the WNPSH using $H$. The $H=5880$-m contour has been widely adopted to determine the boundary of the WNPSH (e.g., Yamaguchi and Majumdar 2010; Kim et al. 2012; Ren et al. 2013), and the operational western boundary index of the WNPSH is defined as the longitude of the westernmost location of this contour (Chen 1999; Liu et al. 2012). As shown by the contours in Fig. 3a, the area of the $H=5880$ -

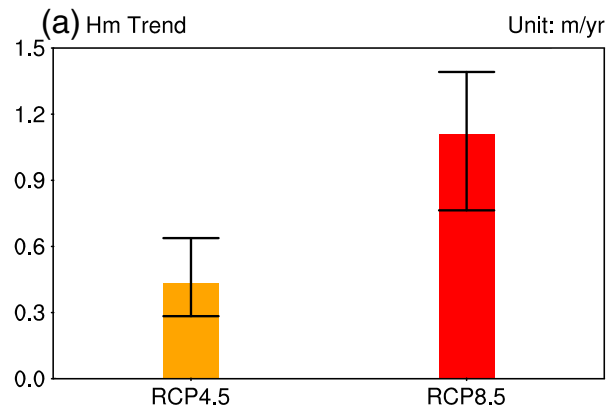

(b) $\mathrm{Hm} \& \mathrm{Tm}$

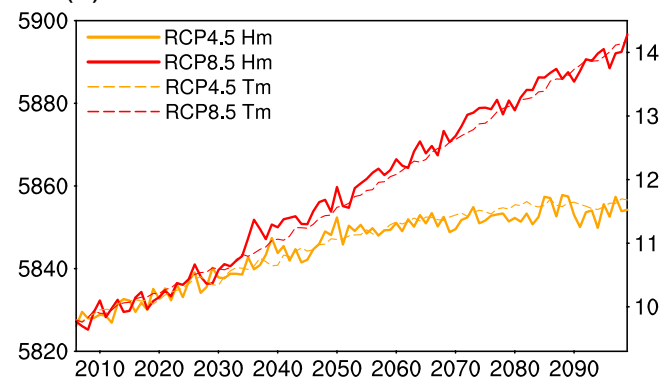

Fig. 2 a The trend of $H_{m}$ (the averaged $H$ over the latitudinal band of $0^{\circ} \mathrm{N}-40^{\circ} \mathrm{N}$ ) for the period of 2006-2099 projected by MMM (thick bars) and the 10th and 90th percentiles estimated by the individual models (thin black bars). b The time series of $H_{m}$ (thick lines and left $y$ axis; unit $\mathrm{m}$ ) and $T_{m}$ (thin dashed lines and right $y$ axis; unit ${ }^{\circ} \mathrm{C}$ ) projected by MMM. Orange and red lines denote the RCP4.5 and RCP8.5, respectively (a) Model IASD \& H

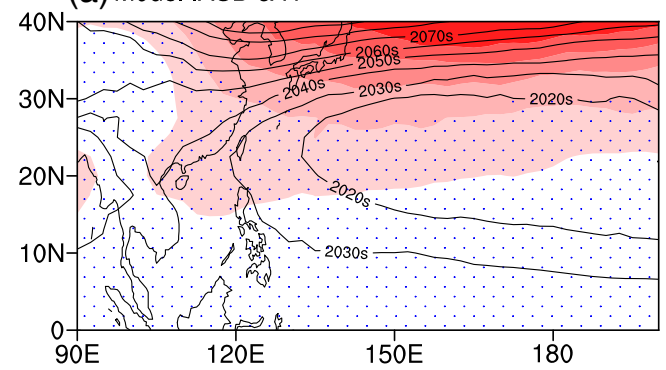

(b) Obs IASD \& corrected $\mathrm{H}$

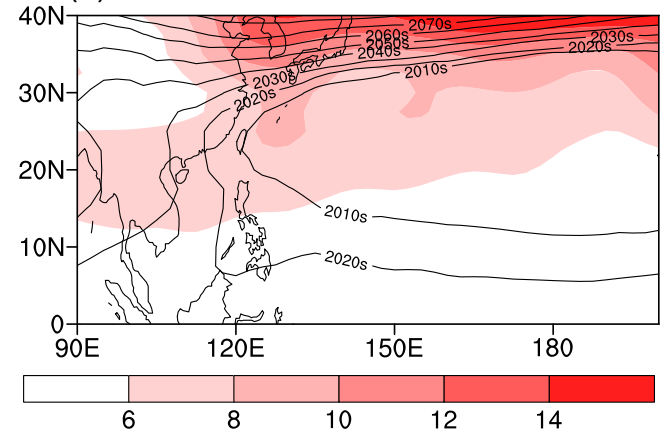

Fig. 3 a The MMM-simulated interannual standard deviation of $H$ (the standard deviation of the 8-year high-pass-filtered time series) in the historical run (shading) and the simulated $H=5880-\mathrm{m}$ contour for each decade in twenty-first century under RCP8.5 (contours). The regions with an interannual standard deviation less than $8.8 \mathrm{~m}$ are stippled. b The interannual standard deviation of $H$ derived from NCEP/NCAR reanalysis (shading) and the bias-corrected contour of $H=5880 \mathrm{~m}$ for each decade in twenty-first century under RCP8.5 (contours)

$m$ contour expands, and its western boundary shifts westward rapidly. After the 2040s, the $H$ values over almost the entire subtropical WNP exceed $5880 \mathrm{~m}$, and the western boundary of the WNPSH cannot be defined by the $H=5880$-m contour thereafter. Previous studies suggested that the $H$ over the WNP is underestimated by the CMIP5 models (Liu et al. 2014; He et al. 2015). The underestimation of $H$ is mostly contributed by the cold bias in the models (figure not shown). If this bias is corrected by adding the underestimated $H$ value to the projected $H$ field, the western boundary of the WNPSH cannot be defined by the $H=5880-\mathrm{m}$ contour after the 2030s (contours in Fig. 3b). The problem of invalid western boundary also appears in the twenty-first century if RCP4.5 or RCP2.6 scenario is adopted (figure not shown). Besides an invalid western boundary, spurious positive long-term trends of the WNPSH caused by the rising $H_{m}$ (Yang and Sun 2003; Huang et al. 2015; Huang and Li 2015; Wu and Wang 2015) will probably continue in the future.

Although the rising trend of $H$ is usually removed in scientific researches focusing on the interannual variability, however, the anomaly in operational practice is obtained by subtracting the climatology of a 30-year reference period. Following the recommendation of the World Meteorological Organization (WMO), the climatology is updated every 10 years (Livezey et al. 2007; Arguez and Vose 2011). For 
example, when discussing whether the WNPSH during 20112020 (2001-2010) are anomalously strong or weak, the corresponding climatology for the 1981-2010 (1971-2000) period should be adopted as a reference. The anomaly always lags the center of the reference period for 15-25 years, and on average, the anomaly lags the climatology for 20 years. As noted by Livezey et al. (2007), there is an extra lag of 2-3 years during which a new climatology is constructed and released. For example, the 1981-2010 climatology is likely to be released to substitute the 1971-2000 climatology in 2013 but not in January 1, 2011. However, as we will show later, a lag of only 20 years is enough to cause problems in characterizing the interannual variability of WNPSH.

As noted by both the MMM simulation (Fig. 3a) and reanalysis data (Fig. 3b), the amplitude of interannual variability (defined by the standard deviation of 8-year high-pass-filtered $H$ ) is smaller than $8 \mathrm{~m}$ at almost all grid points within the WNPSH. However, the MMM-projected rise of $H_{m}$ in 20 years is $22.2 \mathrm{~m}$ under RCP8.5 and $8.8 \mathrm{~m}$ under RCP4.5 (see Fig. 2a), which are greater than the interannual variability of $H$. Compared with an out-of-date climatology with much lower $H_{m}$, positive anomalies of $H$ would be obtained at almost all grid points in almost every year. Based on the positive anomalies of $H$, the WNPSH would be interpreted as anomalously wide, strong, and westward extended in almost every year, and the interannual variability of the WNPSH cannot be objectively monitored.

Under the warming climate, we encounter two major difficulties when measuring the WNPSH with the traditional $H$ metric. First, the western boundary of the WNPSH as defined by the widely used $H=5880-$ m contour would become invalid in the near future, as a result of the increasing $H_{m}$. Second, the rapidly rising $H_{m}$, which has a negligible effect on circulation, would give rise to spurious information regarding the interannual variability and long-term change of the WNPSH. Although the widely used $H$ metric performs well in an unchanged climate, it may not be suitable in a warming climate. It is necessary to look for a new operational metric that applies to the warming climate. This new metric should be convenient to use, and it should be a useful tool for diagnosing the climate phenomena associated with the WNPSH.

\section{A comparison between the $H$ metric and the $H_{e}$ metric under the warming climate}

Given that the WNPSH is a planetary wave (Ting 1994; Chen et al. 2001; Rodwell and Hoskins 2001; Miyasaka and Nakamura 2005), previous studies have suggested that the WNPSH be measured with $H_{e}$ (Zhou et al. 2009; Huang et al. 2015; Huang and Li 2015; Wu and Wang 2015), which is the difference between $H$ and $H_{m}$. Motivated by these studies, we modify the definitions of the area, intensity, and western boundary indices of the WNPSH by substituting $H$ with $H_{e}$ and substituting the $H=5880-\mathrm{m}$ contour with the $H_{e}=0$-m contour. The modified definitions for the area, intensity, and western boundary indices are listed below, in comparison with the current operational definitions by CMA (Chen 1999; Liu et al. 2012; Liu et al. 2014).

- Area index, the area of the region enclosed by the boundary of the WNPSH. This was calculated as the number of grid points with $H \geq 5880 \mathrm{~m}$ over $110^{\circ} \mathrm{E}-180^{\circ} \mathrm{E}, 10^{\circ} \mathrm{N}-$ $85^{\circ} \mathrm{N}$. We suggest that the area index be calculated as the number of grid points with $H_{e} \geq 0 \mathrm{~m}$. A higher (lower) area index means that the area of WNPSH is larger (smaller).

- Intensity index, the volume of the WNPSH in threedimensional space. This was calculated as the sum of $H$ minus $5870 \mathrm{~m}$ for all the grid points with $H \geq 5880 \mathrm{~m}$ over $110^{\circ} \mathrm{E}-180^{\circ} \mathrm{E}, 10^{\circ} \mathrm{N}-85^{\circ} \mathrm{N}$. We suggest that the intensity index be calculated as the sum of $H_{e}$ for the grid points with $H_{e} \geq 0 \mathrm{~m}$ over the same region. A higher (lower)intensity index indicates a stronger (weaker) WNPSH.

- Western boundary index, the location of the western boundary of the WNPSH. This was defined as the longitude of the westernmost grid point with $H \geq 5880$ m over $90^{\circ} \mathrm{E}-180^{\circ} \mathrm{E}$. We suggest that the western boundary index be defined as the longitude of the westernmost grid point with $H_{e} \geq 0 \mathrm{~m}$ over $90^{\circ} \mathrm{E}-180^{\circ} \mathrm{E}$. A higher (lower) western boundary index indicates an anomalous eastward retreat (westward extension) of the WNPSH.

Using the CMIP5 model outputs, the applicability of the $H_{e}$ metric in the future warming climate is assessed in Sect. 4.1, in comparison with the widely used $H$ metric. Using observational data, a comparison between these two metrics is presented in Sect. 4.2 to investigate the applicability of the $H_{e}$ metric to observations.

\subsection{A comparison between the $H$ metric and the $H_{e}$ metric in model simulations}

The western boundary of the WNPSH was considered to be an important indicator of the rain belt on the western flank of the WNPSH (Ren et al. 2013; Hu et al. 2014), and the $H=5880-\mathrm{m}$ contour was widely used to discriminate between the dry areas within the WNPSH and the rainy regions on its western flank (e.g., Ren et al. 2013). However, as shown in the scatter plot of the rainfall- $H$ relationship (Fig. $4 \mathrm{a}$ ), it is clear that the rainfall$H$ relationship changes as the temperature rises. Compared to the historical simulation (blue line in Fig. 4a), the least squares regression line of rainfall with respect to $H$ shifts rightward in RCP4.5 and RCP8.5 simulations (orange and red lines in Fig. 4a), and stronger rightward shift is seen in RCP8.5 simulation with stronger warming. But, little changes are seen in the slopes of the lines. In other words, a fixed intensity of 
(a) $\operatorname{Pr}(\mathrm{H})$

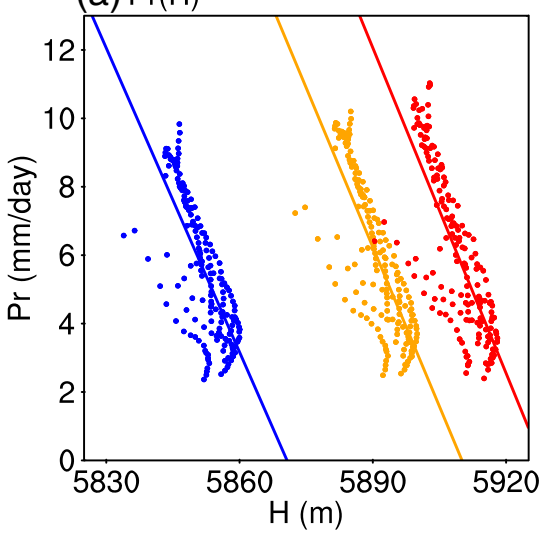

Fig. 4 a A scatter plot of the relationship between $H$ ( $x$ axis) and rainfall $\left(y\right.$ axis) for all the grid points within $10^{\circ} \mathrm{N}-30^{\circ} \mathrm{N}, 130^{\circ} \mathrm{E}-180^{\circ} \mathrm{E}$. b A scatter plot of the relationship between $H_{e}$ ( $x$ axis) and rainfall ( $y$ axis). The historical (1950-1999 averaged), RCP4.5 (2050-2099 averaged),

precipitation is associated with a higher $H$ value in a warmer climate. Therefore, we could not expect to relate the local rainfall to a fixed magnitude of $H$ (e.g., $H=5880$ - or $H=5870-\mathrm{m}$ contour) in a warming climate.

In contrast to the changing rainfall- $H$ relationship, the relationship between rainfall and $H_{e}$ is consistent across different climate backgrounds (Fig. $4 \mathrm{~b}$ ). The least squares regression lines for the historical, RCP4.5, and RCP8.5 simulations almost overlap each other. For these three simulations, the linear relationships between rainfall and $H_{e}$ are all statistically significant at the $99 \%$ confidence level, according to the Student's $t$ test. This evidence suggests that it is more reasonable to relate the abundance of rainfall to a fixed $H_{e}$ contour rather than a fixed $H$ contour under warming climate conditions.

To determine which metric is most suitable for quantitatively measuring the WNPSH under the future warming climate, the time series for the area, intensity, and western boundary indices of the WNPSH under RCP8.5 are shown in Fig. 5, based on the $H_{e}$ metric and the $H$ metric. Because the mean state of $H$ over the WNP is underestimated by most CMIP5 models (Liu et al. 2014; He et al. 2015), a simple bias correction is made and the bias-corrected time series are shown as dashed lines in Fig. 5. Based on the $H$ metric, both the original and bias-corrected time series indicate a rapid expansion, intensification, and westward extension of WNPSH in the twenty-first century (lines in Fig. 5), consistent with the results based on the four best CMIP5 models (Liu et al. 2014). Based on the original (bias-corrected) $H$ field, the western boundary index of the WNPSH will become invalid after about 2045 (2035) under the $H$ metric (Fig. 5c).

As consistently shown by previous climate projection studies, the impact of global warming on East Asian climate is moderate, characterized by a generally unchanged location of the Meiyu (also called Baiu in Japanese or Changma in (b) $\operatorname{Pr}(\mathrm{He})$

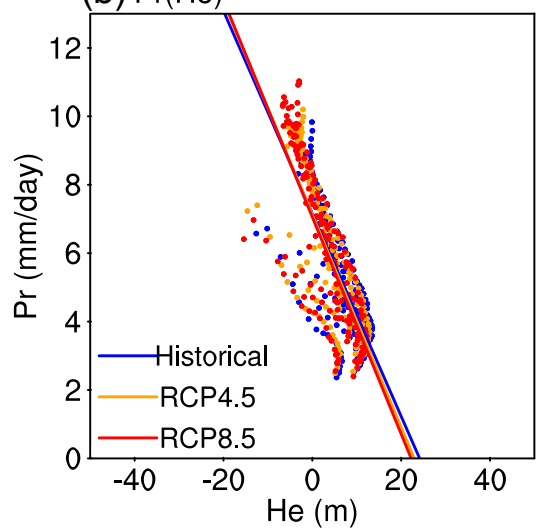

and RCP8.5 (2050-2099 averaged) experiments are plotted in blue, orange, and red, respectively. The straight line is the least squares regression line for each simulation. The unit for rainfall is $\mathrm{mm} /$ day, and the unit for $H$ and $H_{e}$ is meters

Korean) belt (Seo et al. 2013) and modest changes in the East Asian monsoon region (Kitoh et al. 2013). The WNPSH at $500 \mathrm{hPa}$ is expected to weaken and retreat eastward in response to global warming, and the magnitudes of the changes will also be modest (He et al. 2015). Therefore, the strong trends of expansion, intensification, and westward extension shown by the $H$ metric (lines in Fig. 5) are inconsistent with the projected future changes in circulation and rainfall.

(a) Area Index

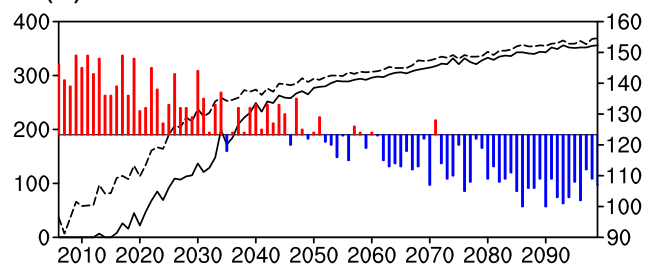

(b) Intensity Index

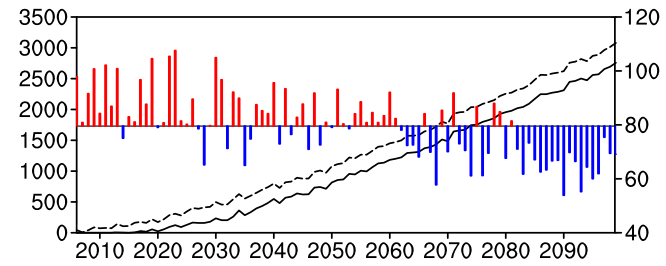

(c) Western Boundary Index

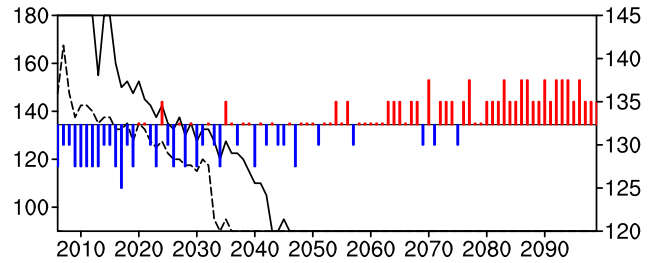

Fig. 5 The MMM-projected time series of area (a), intensity (b), and western boundary (c) indices defined based on the $H$ metric (lines; with left $y$ axis) and the $H_{e}$ metric (bars; with right $y$ axis) under RCP8.5. The solid (dashed) lines are based on the original (bias-corrected) $H$ field 
Contrary to the $H$ metric, the indices based on the $H_{e}$ metric show a moderate trend toward a contracted area, weakened intensity, and eastward retreat of the western boundary (bars in Fig. 5). The area index decreases from approximately 143 at the beginning (2006-2015) to approximately 105 at the end (2090-2099) of the twenty-first century. The intensity index decreases from about $90 \mathrm{~m}$ at the beginning to about $65 \mathrm{~m}$ at the end of the twenty-first century. The western boundary retreats from about $129^{\circ} \mathrm{E}$ at the beginning to about $136^{\circ} \mathrm{E}$ at the end of the twenty-first century, consistent with He et al. (2015). Unlike the invalid western boundary index based on $H$ metric, all three indices can be well defined throughout the twenty-first century using $H_{e}$ metric.

The evidence presented above based on CMIP5 models suggests that the rainfall- $H_{e}$ relationship is more robust than the rainfall- $H$ relationship. The area, intensity, and western boundary indices could be defined well using $H_{e}$ metric if the warming trend continues. The projected long-term trends of the area, intensity, and western boundary indices based on $H_{e}$ are consistent with the projected changes in circulation and rainfall. Given the inevitable bias of the models, it still must be addressed whether the $H_{e}$ metric is applicable to observation data for recent decades.

\subsection{A comparison between the $H$ metric and the $H_{e}$ metric with respect to observation data}

A good metric of the WNPSH should have a robust relationship with rainfall, and the relationship is expected to change little among different climate backgrounds. Many previous studies reported a decadal climate change over the WNP in the late 1970s (Gong and Ho 2002; Zhou et al. 2009; Huang et al. 2015). To compare the robustness of the $H$ metric and the $H_{e}$ metric to this decadal climate change, we investigated the relationship of the $500-\mathrm{hPa}$ vertical velocity (W500) with $H$ and $H_{e}$ using NCEP/NCAR reanalysis data (Fig. 6), given the lack of credible rainfall data over the WNP before 1979 . Compared to the 1949-1978 period, a substantial rightward shift is seen in the regression line of W500- $H$ relationship for the 1979-2014 period (Fig. 6a), similar to the rightward shift in the global warming simulations by CMIP5 models (see Fig. 4a). This observational evidence reinforces the impossibility of relating the abundance of rainfall to a fixed contour of $H$ under the warming climate. However, a much smaller difference between the two periods is seen in the $\mathrm{W} 500-H_{e}$ relationship (Fig. 6b), suggesting that the $\mathrm{W} 500-H_{e}$ relationship is more robust than the W500- $H$ relationship. Similar results could be obtained (figure not shown) if ERA40 reanalysis data (Uppala et al. 2005) is used instead of NCEP/NCAR data. Because stronger ascending motion is closely associated with more abundant rainfall, the rainfall- $H_{e}$ relationship should also be more robust than the rainfall- $H$ relationship.

The time series for area, intensity, and western boundary indices of the WNPSH derived from NCEP/NCAR data are shown in Fig. 7, as measured by the $H$ metric and the $H_{e}$ metric. Based on the $H$ metric, the area, intensity, and western boundary indices showed substantial decadal changes during the late 1970s, which could be interpreted as expansion, enhancement, and westward extension of the WNPSH. However, these three indices based on the $H_{e}$ metric showed a modestly contracted area, reduced intensity, and eastward retreat of the western boundary. The decadal changes seen in the indices based on the $H_{e}$ metric are consistent with the circulation changes revealed by previous studies (Huang et al. 2015; Huang and Li 2015; Wu and Wang 2015).

The WMO recommended that an "anomaly" in operational practice be defined by subtracting the climatology of a 30-year reference period. In a warming climate with rising $H_{m}$, an outof-date climatology may lead to a spurious anomaly under the $H$ metric. An example is shown in Fig. 7c for the western boundary index measured by $H$. Compared to the 19511980 climatology (blue horizontal line in Fig. 7c), anomalous westward extension of the WNPSH is seen in 8 of the 10 years during 1981-1990. Compared to the 1961-1990 climatology (green horizontal line in Fig. 7c), anomalous westward extension of the WNPSH is seen in all the 10 years during 1991-
Fig. 6 a Scatter plot of the W500- $H$ relationship based on NCEP/NCAR reanalysis. b Scatter plot of the W500- $H_{c}$ relationship. The blue and red dots are for the 1949-1978 epoch and the 1979-2014 epoch, respectively. The lines are the least squares regression lines for each epoch. The unit for W500 is $10^{-2} \mathrm{~Pa} / \mathrm{s}$, and the unit for $H$ and $H_{e}$ is meters (a) $\mathrm{W} 500(\mathrm{H})$
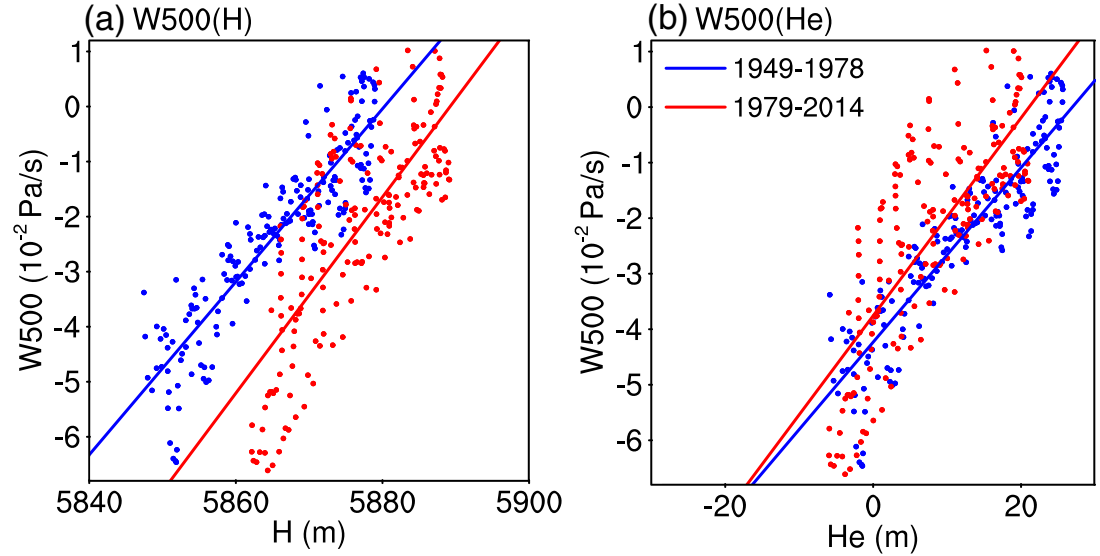
(a) Area Index

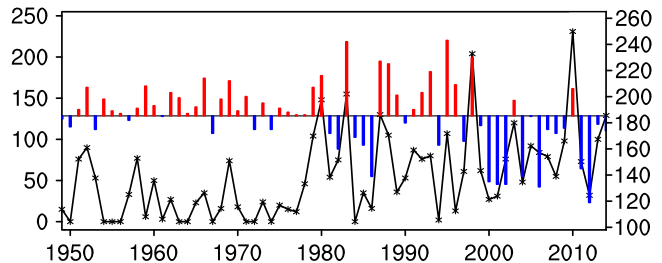

(b) Intensity Index

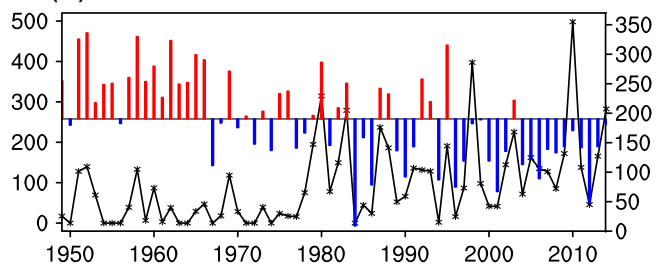

(c) Western Boundary Index

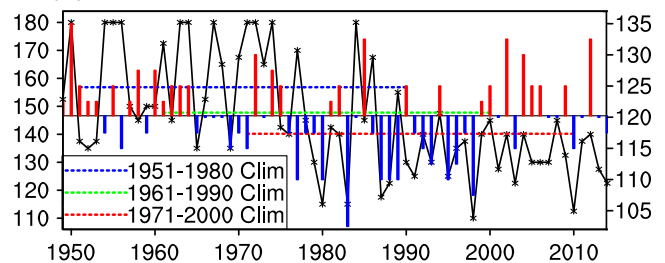

Fig. 7 The time series of area (a), intensity (b), and western boundary (c) indices in NCEP/NCAR reanalysis, based on the $H$ metric (black lines; left $y$ axis) and $H_{e}$ metric (bars; right $y$ axis). In c, the blue, green, and red horizontal dotted lines are the time-averaged western boundary indices based on the $H$ metric for the 1951-1980, 1961-1990, and 1971-2000 periods, respectively

2000. Compared to the 1971-2000 climatology (red horizontal line in Fig. 7c), anomalous westward extension of WNPSH is seen in 9 of the 10 years during 2001-2010.

Despite the fact that there may have been real decadal trends of the WNPSH in past decades, a strong rising trend of $H_{m}$ without accompanying changes in circulation could also result in spurious anomalies based on the $H$ metric. In such circumstances, the WNPSH would be taken as anomalously wide, strong, and westward extended in almost every year. This spurious information regarding the interannual variability of the WNPSH may further obstruct the prediction of climate phenomena related to the WNPSH. As already shown in Fig. 3, the rising trend of $H_{m}$ is strong enough to overwhelm the interannual variability of $H$ over the WNP under both RCP4.5 and RCP8.5. Therefore, cautions should be taken when measuring the WNPSH with the $H$ metric. However, we would not encounter such problems if we used $H_{e}$ metric, since the rising trend of $H_{m}$ is automatically removed when calculating $H_{e}$.

The WNPSH indices were widely used as a benchmark for monitoring and predicting the interannual variability of East Asian summer rainfall (Liu et al. 2012). Here, we tested which metric more closely relates the WPNSH to interannual rainfall variability, using the data spanning 1979-2014 period due to the lack of reliable rainfall data before 1979 . To focus on the

interannual variability, 8-year, high-pass Fourier filter is applied to the rainfall, W500, and $850-\mathrm{hPa}$ water vapor transport, and the interannual anomalies of these variables are obtained. Figure 8 shows the regression coefficients of these interannual anomalies onto the western boundary indices of WNPSH shown in Fig. 7c.

Compared to the regression field based on the $H$ metric (Fig. 8a), more areas with rainfall anomalies exceeding the 95\% confidence level are seen based on the $H_{e}$ metric (Fig. 8b). In particular, the well-known meridional triple pattern of interannual rainfall variability in eastern China (e.g., Sun and Wang 2015) is captured by the $H_{e}$ metric. When the WNPSH is abnormally westward extended, both GPCP and CMAP data show positive rainfall anomalies along the Yangtze-Huai River, accompanied by negative rainfall anomalies over south China and north China (Fig. 8b). Consistent with the regressed rainfall anomalies, the regressed anomalies of vertical motion and horizontal water vapor transport are also stronger and more statistically significant if the western boundary index is defined by the $H_{e}$ metric (Fig. 8c, d). This evidence suggests that the $H_{e}$ metric better captures the

(a) H-metric

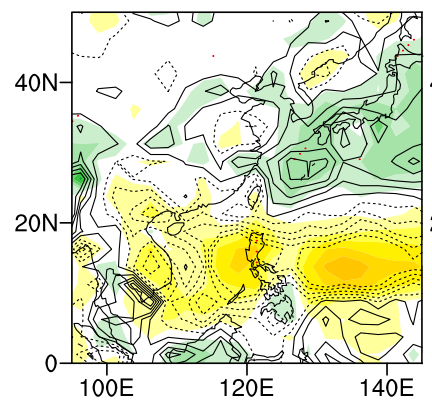

(c) H-metric

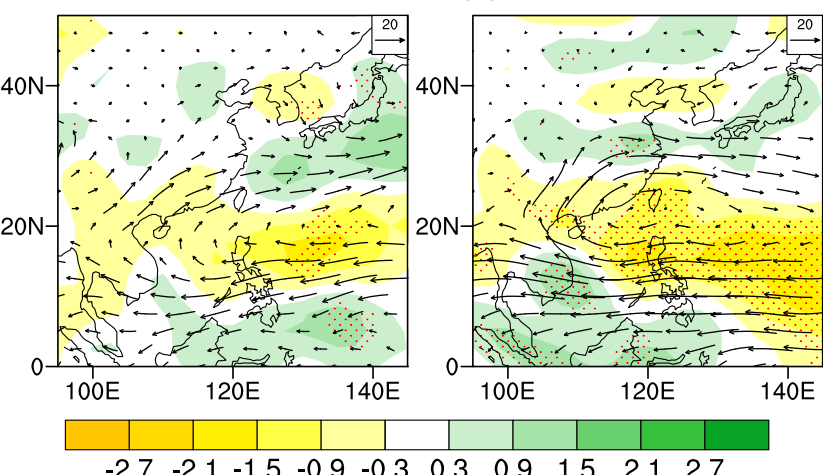

Fig. 8 a The regressed anomalies of interannual rainfall variability (unit $\mathrm{mm} /$ day) with respect to the western boundary index based on $H$ metric (multiplied by -1), as shown in Fig. 7c. Shadings and contours are based on GPCP and CMAP datasets, respectively. b Similar to a but are regressed onto the western boundary index based on $H_{e}$ metric. c, d Similar to $\mathbf{a}, \mathbf{b}$ but are regressed anomalies of $500-\mathrm{hPa}$ vertical velocity (unit $-1 \times 10^{-2} \mathrm{~Pa} / \mathrm{s}$ ) and $850-\mathrm{hPa}$ horizontal water vapor transport (vectors; unit $10^{-3} \mathrm{~m} / \mathrm{s}$ ). The stippled regions indicate that the regressed anomalies of rainfall (a, b) and 500-hPa vertical velocity (c, d) are statistically significant at the $95 \%$ confidence level 
relation of the WNPSH with the interannual variability of East Asia summer rainfall. Similarly, the $H_{e}$ metric also outperforms the $H$ metric in terms of the area and the intensity indices of WNPSH under the warming climate (figure not shown).

Based on CMIP5 model simulations and NCEP/NCAR reanalysis data, the evidence presented here suggests that the $H_{e}$ metric is applicable to characterize the WNPSH under a changing climate. Previous studies have adopted other variables to overcome the difficulties caused by a rising $H_{m}$, such as relative vorticity (Yang and Sun 2003; Qian and Shi 2016) and stream function (Li et al. 2012). However, relative vorticity is not good at characterizing the shape of the WNPSH (Huang et al. 2015). Although stream function captures the shape of the WNPSH as well as $H_{e}$ (Li et al. 2012; He et al. 2015), it is hard to calculate the stream function by solving Poisson equation using global wind field. However, it is much easier to calculate $H_{e}$ using the $H$ data within the $0^{\circ} \mathrm{N}-40^{\circ} \mathrm{N}$ region, for both grid data and station observations. Therefore, the $H_{e}$ metric can be widely used as the operational metric of the WNPSH under the warming climate.

\section{Summary}

In this study, we investigate how to characterize the key features of the WNPSH under the warming climate. Due to the systematic rise of $H$ under the warming climate, we would face difficulties when measuring the WNPSH with the traditional $H$ metric. To understand the mechanism for an increasing $H$ due to global warming, the projected change of $H$ is decomposed according to the hypsometric equation. Using CMIP5 model outputs and reanalysis data, the applicability of the $H_{e}$ metric (Zhou et al. 2009; Huang et al. 2015; Huang and Li 2015; Wu and Wang 2015) to the warming climate is investigated with respect to the traditional $H$ metric. The major conclusions are summarized as follows:

1. As determined by both theoretical formulation of the hypsometric equation and CMIP5 model projections, the zonal mean $H\left(H_{m}\right)$ over the subtropical northern hemisphere is rising because of global warming. The MMM-projected linear trend of $H_{m}$ for the twenty-first century is $0.44 \mathrm{~m} /$ year under RCP4.5 and $1.11 \mathrm{~m} /$ year under RCP8.5. Decomposition according to the hypsometric equation suggests that more than $80 \%$ of the increase in $H$ are attributable to spatial uniform warming, which has a negligible impact on circulation. The response of WNPSH circulation to global warming is determined by the change in $H$ gradient, especially the meridional $H$ gradient, which is mostly attributable to the change in temperature pattern, independent of the systematic rise in $H_{m}$.

2. The rising trend of $H_{m}$ due to global warming gives rise to difficulties when measuring the WNPSH with the traditional $H$ metric. Due to the rising $H_{m}$, any fixed contour of $H$ expands rapidly. Spurious expanding, enhancing, and westward extending trends may be interpreted from the rising $H_{m}$. The western boundary of WNPSH may become invalid in a few decades if the current warming trend continues. Under both RCP4.5 and RCP8.5 scenarios, the rising trends of $H$ are strong enough to overwhelm the interannual variability of $H$ over the WNP. In operational practice, spurious anomalies on interannual timescales would result from comparing the current $H$ value to the out-ofdate climatology of the past 30-year period.

3. The $H_{e}$ metric effectively captures the variation of the WPNSH under the warming climate. Compared to $H$, $H_{e}$ is a better indicator of the abundance of rainfall, and the rainfall- $H_{e}$ relationship remains generally unchanged under different climate backgrounds. The area, intensity, and western boundary indices of the WNPSH can be effectively defined using the $H_{e}$ metric, and the long-term trends of these three indices are consistent with the projected changes in circulation. Finally, the indices defined by the $H_{e}$ metric effectively capture the relationship of the WNPSH to the interannual rainfall variability of East Asia.

Despite similar performance of the $H$ metric and the $H_{e}$ metric under an unchanged climate, the $H_{e}$ metric is more suitable under a changing climate, especially in the current warming climate characterized by a rapidly rising $H_{m}$. We recommend that the WNPSH be measured with $H_{e}$ by removing the simultaneous $H_{m}$ from the original $H$ field. We also recommend the WNPSH indices be defined by the $H_{e}=0-\mathrm{m}$ contour instead of the $H=5880$-m contour. Besides WNPSH, the $H_{e}$ metric may also be suitable for measuring other high/low-pressure systems, ridges, and troughs under the warming climate, such as the Indian-Burma trough (Wang et al. 2011) and the South Asia High (Wei et al. 2014; Xue et al. 2015; Qu et al. 2015).

Acknowledgements We wish to thank the NOAA and PCMDI who provided the observational data and model data. The observational data were obtained via the NOAA website (http://www.esrl.noaa. gov/psd/data/), and the model data were obtained via the PCMDI website (http://pcmdi.llnl.gov). This work was supported by National Basic Research Program of China (2014CB953901), National Natural Science Foundation of China (41505067, 41330423, 41575043, 41375095, 41675096), and Science and Technology Program of Guangzhou (201607010153).

Open Access This article is distributed under the terms of the Creative Commons Attribution 4.0 International License (http:// creativecommons.org/licenses/by/4.0/), which permits unrestricted use, distribution, and reproduction in any medium, provided you give appropriate credit to the original author(s) and the source, provide a link to the Creative Commons license, and indicate if changes were made. 


\section{References}

Adler RF, Huffman GJ, Chang A et al (2003) The version-2 Global Precipitation Climatology Project (GPCP) monthly precipitation analysis (1979-present). J Hydrometeorol 4(6):1147-1167. doi:10.1175/1525-7541(2003)004<1147:tvgpcp >2.0.co;2

Arguez A, Vose RS (2011) The definition of the standard WMO climate normal: the key to deriving alternative climate normals. B Am Meteorol Soc 92(6):699-704. doi:10.1175/2010BAMS2955.1

Chen G (1999) The subtropical high. In: Zhao ZG (ed) The droughts and floods in summer in China and background fields. China Meteorol Press, Beijing, pp. 45-52 (In Chinese)

Chen P, Hoerling MP, Dole RM (2001) The origin of the subtropical anticyclones. J Atmos Sci 58(13):1827-1835. doi:10.1175/15200469(2001)058<1827:tootsa $>2.0 . c 0 ; 2$

Chen Z, Wen Z, Wu R, Lin X, Wang J (2016) Relative importance of tropical SST anomalies in maintaining the western North Pacific anomalous anticyclone during el Niño to La Niña transition years. Clim Dynam 46(3):1027-1041. doi:10.1007/s00382-015-2630-1

Gleckler PJ, Taylor KE, Doutriaux C (2008) Performance metrics for climate models. Journal of Geophysical Research: Atmospheres 113(D6):D06104. doi:10.1029/2007jd008972

Gong DY, Ho CH (2002) Shift in the summer rainfall over the Yangtze River valley in the late 1970s. Geophys Res Lett 29(10):1436. doi:10.1029/2001gl014523

He C, Zhou T, Lin A, Wu B, Gu D, Li C, Zheng B (2015) Enhanced or weakened western North Pacific subtropical high under global warming? Scientific Reports 5:16771. doi:10.1038/srep16771

Holton JR (2004) An introduction to dynamic meteorology, 4 edn. Elsevier Academic Press, Burlington

Hu Y, Zhu Y, Zhong Z, Ha Y (2014) New predictors and a statistical forecast model for Mei-Yu onset date in the middle and lower reaches of the Yangtze River valley. Weather Forecast 29(3):654 665. doi:10.1175/waf-d-13-00109.1

Huang Y, Li X (2015) The interdecadal variation of the western Pacific subtropical high as measured by $500 \mathrm{hPa}$ eddy geopotential height. Atmospheric and Oceanic Science Letters 8(6):371-375. doi:10.3878/AOSL20150038

Huang Y, Wang H, Fan K, Gao Y (2015) The western Pacific subtropical high after the 1970s: westward or eastward shift? Clim Dynam 44(7-8):2035-2047. doi:10.1007/s00382-014-2194-5

Jiang X, Li Y, Yang S, Shu J, He G (2015) Interannual variation of midsummer heavy rainfall in the eastern edge of the Tibetan Plateau. Clim Dynam 45(11):3091-3102. doi:10.1007/s00382-015-2526-0

Kalnay E, Kanamitsu M, Kistler R et al (1996) The NCEP/NCAR 40year reanalysis project. B Am Meteorol Soc 77(3):437-471. doi:10.1175/1520-0477(1996)077<0437:tnyrp >2.0.co;2

Kim J-H, Ho C-H, Kim H-S, Choi W (2012) 2010 western North Pacific typhoon season: seasonal overview and forecast using a trackpattern-based model. Weather Forecast 27(3):730-743. doi:10.1175/waf-d-11-00109.1

Kitoh A, Endo H, Krishna Kumar K, Cavalcanti IFA, Goswami P, Zhou T (2013) Monsoons in a changing world: a regional perspective in a global context. Journal of Geophysical Research: Atmospheres 118(8):3053-3065. doi:10.1002/jgrd.50258

Li W, Li L, Ting M, Liu Y (2012) Intensification of northern hemisphere subtropical highs in a warming climate. Nat Geosci 5(11):830-834. doi:10.1038/ngeo1590

Lin AL, Li CH, Gu DJ, Zheng B (2012) Variation and causes of persistent drought events in Guangdong Province. J Trop Meteorol 18(1):54 64. doi:10.3969/j.issn.1006-8775.2012.01.006

Liu Y, Li W, Ai W, Li Q (2012) Reconstruction and application of monthly western Pacific subtropical high indices. Journal of Applied Meteorological Science 23(4):414-423
Liu Y, Li W, Zuo J, Hu Z-Z (2014) Simulation and projection of the western Pacific subtropical high in CMIP5 models. J Meteorol Res 28(3):327-340. doi:10.1007/s13351-014-3151-2 (In Chinese)

Livezey RE, Vinnikov KY, Timofeyeva MM, Tinker R, Dool HM (2007) Estimation and extrapolation of climate normals and climatic trends. J Appl Meteorol Climatol 46(11):1759-1776. doi:10.1175/2007 JAMC1666.1

Matsumura S, Sugimoto S, Sato T (2015) Recent intensification of the western Pacific subtropical high associated with the East Asian summer monsoon. J Clim 28(7):2873-2883. doi:10.1175/jcli-d-1400569.1

Miyasaka T, Nakamura H (2005) Structure and formation mechanisms of the northern hemisphere summertime subtropical highs. J Clim 18(23):5046-5065. doi:10.1175/jcli3599.1

Park C-K, Schubert SD (1997) On the nature of the 1994 East Asian summer drought. J Clim 10(5):1056-1070. doi:10.1175/15200442(1997)010<1056:otnote $>2.0 . c 0 ; 2$

Qian W, Shi J (2016) Tripole precipitation pattern and SST variations linked with extreme zonal activities of the western Pacific subtropical high. Int J Climatol. doi:10.1002/joc.4897

Qu X, Huang G, Hu K, Xie S-P, Du Y, Zheng X-T, Liu L (2015) Equatorward shift of the South Asian high in response to anthropogenic forcing. Theor Appl Climatol 119(1):113-122. doi:10.1007 /s00704-014-1095-1

Ren XJ, Yang XQ, Sun XG (2013) Zonal oscillation of western Pacific subtropical high and subseasonal SST variations during Yangtze persistent heavy rainfall events. J Clim 26(22):8929-8946. doi:10.1175/jcli-d-12-00861.1

Rodwell MJ, Hoskins BJ (2001) Subtropical anticyclones and summer monsoons. J Clim 14(15):3192-3211. doi:10.1175/1520-0442(2001 ) $014<3192$ :saasm $>2.0$. co; 2

Sampe T, Xie SP (2010) Large-scale dynamics of the Meiyu-Baiu rain band: environmental forcing by the westerly jet. J Clim 23(1):113134. doi:10.1175/2009jcli3128.1

Seo K-H, Ok J, Son J-H, Cha D-H (2013) Assessing future changes in the East Asian summer monsoon using CMIP5 coupled models. J Clim 26(19):7662-7675. doi:10.1175/jcli-d-12-00694.1

Sun B, Wang H (2015) Inter-decadal transition of the leading mode of inter-annual variability of summer rainfall in East China and its associated atmospheric water vapor transport. Clim Dynam 44(910):2703-2722. doi:10.1007/s00382-014-2251-0

Taylor KE, Stouffer RJ, Meehl GA (2012) An overview of CMIP5 and the experiment design. B Am Meteorol Soc 93(4):485-498. doi:10.1175/bams-d-11-00094.1

Ting M (1994) Maintenance of northern summer stationary waves in a GCM. J Atmos Sci 51(22):3286-3308. doi:10.1175/1520-0469 (1994)051<3286:monssw>2.0.co;2

Uppala SM, Kallberg PW, Simmons AJ et al (2005) The ERA-40 reanalysis. Q J Roy Meteor Soc 131(612):2961-3012. doi:10.1256 /qj.04.176

Vuuren D, Edmonds J, Kainuma M, Riahi K, Thomson A, Hibbard K, Hurtt G, Kram T, Krey V, Lamarque J-F, Masui T, Meinshausen M, Nakicenovic N, Smith S, Rose S (2011) The Representative Concentration Pathways: an overview. Clim Chang 109(1-2):531. doi:10.1007/s10584-011-0148-Z

Wang T, Yang S, Wen Z, Wu R, Zhao P (2011) Variations of the winter India-Burma trough and their links to climate anomalies over southern and eastern Asia. Journal of Geophysical Research: Atmospheres 116(D23):D23118. doi:10.1029/2011jd016373

Wang W, Zhou W, Li X, Wang X, Wang D (2016) Synoptic-scale characteristics and atmospheric controls of summer heat waves in China. Clim Dynam 46(9):2923-2941. doi:10.1007/s00382-015-2741-8

Wei W, Zhang R, Wen M, Rong X, Li T (2014) Impact of Indian summer monsoon on the South Asian High and its influence on summer rainfall over China. Clim Dynam 43(5-6):1257-1269. doi:10.1007 /s00382-013-1938-y 
Wen N, Liu Z, Liu Y (2015) Direct impact of El Niño on East Asian summer precipitation in the observation. Clim Dynam 44(11-12): 2979-2987. doi:10.1007/s00382-015-2605-2

Wu B, Zhou TJ (2008) Oceanic origin of the interannual and interdecadal variability of the summertime western Pacific subtropical high. Geophys Res Lett 35(13):L13701. doi:10.1029/2008g1034584

Wu L, Wang B, Geng S (2005) Growing typhoon influence on East Asia. Geophys Res Lett 32(18):L18703. doi:10.1029/2005g1022937

Wu L, Wang C (2015) Has the western Pacific subtropical high extended westward since the late 1970s? J Clim 28(13):5406-5413. doi:10.1175/jcli-d-14-00618.1

Xie PP, Arkin PA (1997) Global precipitation: a 17-year monthly analysis based on gauge observations, satellite estimates, and numerical model outputs. B Am Meteorol Soc 78(11):2539-2558. doi:10.1175/1520-0477(1997)078<2539:gpayma>2.0.co;2

Xue X, Chen W, Nath D, Zhou D (2015) Whether the decadal shift of South Asia high intensity around the late 1970 s exists or not. Theor Appl Climatol 120(3):673-683. doi:10.1007/s00704-014-1200-5

Yamaguchi M, Majumdar SJ (2010) Using TIGGE data to diagnose initial perturbations and their growth for tropical cyclone ensemble forecasts. Mon Weather Rev 138(9):3634-3655. doi:10.1175/2010mwr3176.1
Yang H, Sun SQ (2003) Longitudinal displacement of the subtropical high in the western Pacific in summer and its influence. Adv Atmos Sci 20(6):921-933

Yun K-S, Yeh S-W, Ha K-J (2015) Covariability of western tropical Pacific-North Pacific atmospheric circulation during summer. Scientific Reports 5:16980. doi:10.1038/srep16980

Zhang S, Wang S, Zhang Y, Zhang D, Song Y (2004) The climatic character of high temperature and the prediction in the large cities of east of China. J Trop Meteorol 20(6):750-760 (In Chinese)

Zhou TJ, Yu RC (2005) Atmospheric water vapor transport associated with typical anomalous summer rainfall patterns in China. J Geophys Res-Atmos 110:D08104. doi:10.1029/2004jd005413

Zhou TJ, Yu RC, Zhang J, Drange H, Cassou C, Deser C, Hodson DLR, Sanchez-Gomez E, Li J, Keenlyside N, Xin XG, Okumura Y (2009) Why the western Pacific subtropical high has extended westward since the late 1970s. J Clim 22(8):2199-2215

Zhu C, Nakazawa T, Li J, Chen L (2003) The 30-60 day intraseasonal oscillation over the western North Pacific Ocean and its impacts on summer flooding in China during 1998. Geophys Res Lett 30(18): 1952. doi:10.1029/2003g1017817 